\title{
Estimating consolidation parameters from field piezoball tests
}

\author{
C. COLREAVY*, C. D. O’LOUGHLIN* and M. F. RANDOLPH*
}

\begin{abstract}
The piezoball, a ball penetrometer featuring pore pressure measurements, is a relatively new device that is potentially superior to the more commonly used piezocone for profiling fine-grained soils. This is due to lower uncertainty in how to derive soil strength from the net penetration resistance and the option of measuring consolidation characteristics during pauses in the penetration, potentially more quickly than in a piezocone test. This paper presents results from a series of piezoball tests undertaken at a soft clay test site using a piezoball that measures pore pressure concurrently at the ball equator, tip and half-way between the tip and equator, the so-called mid-face position. Analysis of the test data provides strong arguments for measuring pore pressure at both the equator and mid-face positions. The coefficient of consolidation derived from piezoball dissipation data using recently developed numerical solutions is shown to be highly comparable to that deduced from a piezocone dissipation test. This paper shows that the penetration resistance varies significantly with the rate of penetration due to either viscous rate effects or increasing degrees of partial consolidation during penetration, both of which influence the estimation of undrained shear strength and hamper interpretation of dissipation data. Guidance on assessing the drainage response during a piezoball penetration test is provided. Finally, dissipation test data presented in the paper are added to a database formed from centrifuge and field tests that is used to form a new empirical method for estimating the coefficient of consolidation.
\end{abstract}

KEYWORDS: clays; consolidation; penetrometers; pore pressures; shear strength; site investigation

\section{INTRODUCTION}

Consolidation characteristics of soil are an important factor in geotechnical design, including cases where the structure cannot be commissioned until consolidation settlement and strength increases are complete (e.g. offshore gravity structures, reclaimed land and embankments), and when the rate of loading on the structure affects the mobilised soil strength and hence the stability of the structure (e.g. offshore pipelines and mudmats). Often consolidation characteristics are estimated in the laboratory on 'undisturbed' samples. However, in the offshore environment, difficulties and costs involved with retrieving samples of sufficient quality for laboratory testing has led to greater emphasis being placed on in situ testing. The most common method for estimating in situ consolidation parameters is the piezocone dissipation test, where penetration is halted during a cone penetration test (CPT) and the change in excess pore pressure is recorded over time. The time required for significant dissipation is a drawback to the test; in low-permeability soils the time for $50 \%$ dissipation can take several hours. During offshore site investigations, where daily costs can be as much as $\$ 0.5$ million (Randolph et al., 2005), these pauses in the cone penetration can be very expensive.

The advantages of full-flow penetrometers (T-bar or ball penetrometer) have been shown in a number of studies. Chung \& Randolph (2004) showed that the correction required to provide net resistance is much lower than for the cone. Colreavy et al. (2012) demonstrated the higher accuracy of the ball and T-bar over the cone in very soft soil, owing to the ten times larger probe area of the full-flow penetrometers. Remoulded shear strength and sensitivity can

Manuscript received 21 May 2015; revised manuscript accepted 23 September 2015. Published online ahead of print 4 December 2015. Discussion on this paper closes on 1 September 2016, for further details see p. ii.

* Centre for Offshore Foundation Systems, the University of Western Australia, Crawley, WA, Australia. be estimated using full-flow penetrometers by including episodes of cyclic remoulding (e.g. Yafrate \& DeJong, 2009), where the probe is cycled up and down over (typically) four diameters to remould the soil. Bearing capacity factors for converting full-flow penetrometer resistance to soil strength are underpinned by theoretical solutions, with a narrower range than for the cone (Boylan et al., 2007; DeJong et al., 2011). Cone penetration is complex and the penetration resistance is shown to be influenced by soil stiffness and stress and strain anisotropy (Teh \& Houlsby, 1991; Lu et al., 2004), and other factors such as sensitivity and strain rate dependency. The full-flow failure mechanism developed during T-bar and ball penetration leads to a lower dependency of penetration resistance on soil stiffness and anisotropy (Low et al., 2010). Due consideration needs to be paid to the area of the shaft relative to the probe, although a shaft-probe area ratio less than $0 \cdot 15$ is generally acceptable for strength estimations (Lunne et al., 2011).

Pore pressure sensors have generally been incorporated in the ball penetrometer, leading to the term 'piezoball' (Low et al., 2007; DeJong et al., 2008; Colreavy et al., 2010). The most appropriate location for the pore pressure measurement location has been debated in recent studies (DeJong et al., 2008; Boylan et al., 2010; Mahmoodzadeh \& Randolph, 2014), with the current consensus leaning towards concurrent pore pressure measurement at the equator and mid-face positons (Colreavy et al., 2015). Inclusion of pore pressure sensors (particularly at the equator position) aids stratigraphy identification (e.g. Kelleher \& Randolph, 2005), but also allows for an assessment of consolidation characteristics, either during penetration by considering the magnitude of the pressure generated at the mid-face location relative to that at the equator, or during a pause in penetration where the pore pressure is monitored during dissipation, similar to dissipation phases in a piezocone test. Several studies (e.g. Low et al., 2007; Colreavy et al., 2010, 2015) have shown that the non-dimensional dissipation times for the piezoball (accounting for the drainage path lengths associated with 
the penetrometer diameter) are shorter than for the piezocone because of the spherical geometry and less extensive pore pressure field. The piezoball is now a mature technology, with solutions available for interpreting the horizontal coefficient of consolidation, $c_{\mathrm{h}}$, from dissipation data (Mahmoodzadeh et al., 2015). However, relative to the piezocone, experience with the piezoball remains limited.

This paper attempts to address this imbalance by reporting data from field tests using a piezoball that measures pore pressure at the tip, mid-face and equator positions. The tests, which were conducted at an onshore soft clay site, involved variable rate penetration ('twitch') tests followed by dissipation phases. The effect of penetration rate on penetration resistance and excess pore pressure is assessed through the twitch tests, while the horizontal coefficient of consolidation, $c_{\mathrm{h}}$, is estimated from dissipation tests. The observed responses in the tests form the basis for a new empirical method for estimating $c_{\mathrm{h}}$, supplementing fitting dissipation data to a theoretical curve, and the merit of this approach is assessed by considering a database of piezoball-derived $c_{\mathrm{h}}$ values.

\section{SITE DETAILS}

As part of the activities of the Australian Research Council Centre for Geotechnical Science and Engineering, a national field testing facility has been established at a soft clay site near Ballina, New South Wales (Kelly et al., 2014), modelled on the successful Bothkennar soft soil test bed in Scotland (Nash et al., 1992). The facility has been established to advance the understanding of various foundation problems, including embankments, piles and shallow foundations. As part of the overall campaign, extensive site investigation has been undertaken, including shear vane tests, dilatometer tests, self-boring pressuremeter tests and cone and full-flow penetrometer tests; the latter are considered in this paper.

The site is located in the Richmond River floodplain (Fig. 1), where the main sediment of interest is a $10 \mathrm{~m}$ thick soft estuarine clay layer, deposited in the Holocene period following the last glaciation. This clay layer is underlain by sand and overlain by a $1.5 \mathrm{~m}$ thick alluvial silty sand deposit. The area where the tests were carried out is generally level, with a datum of approximately $0.5 \mathrm{~m}$ above sea level and a shallow water table, typically within $1 \mathrm{~m}$ of the soil surface. Pineda et al. (2014) present some of the soil properties of the Ballina clay, as summarised in Table 1.

\section{EQUIPMENT}

A new piezoball, based on an original design described by Boylan et al. (2010), but with simultaneous measurement of pore pressure at the equator, mid-face and tip locations, was designed and built for these field tests (Fig. 2). The piezoball has a diameter of $60 \mathrm{~mm}$ and is connected to a $20 \mathrm{~mm}$ diameter shaft that tapers out to a diameter of $35.7 \mathrm{~mm}$ at a distance $200 \mathrm{~mm}$ ( $3 \cdot 3$ ball diameters) measured from the top of the ball, allowing the penetrometer to be connected to standard cone penetrometer rods. The shaft diameter immediately behind the ball gives a shaft to penetrometer area ratio, $A_{\mathrm{s}} / A_{\mathrm{p}}=0 \cdot 11$, which is below the $15 \%$ threshold recommended by Lunne et al. (2011), such that effects due to unequal pore and overburden pressure are considered negligible. Penetration and extraction resistances are measured by a sleeve-protected strain gauged section located

Table 1. Ballina soil properties (from Pineda et al. (2014))

\begin{tabular}{l|l}
\hline Property & Value \\
\hline Moisture content, $w: \%$ & 105 \\
Liquid limit, $w_{\mathrm{L}}: \%$ & 98 \\
Plastic limit, $w_{\mathrm{P}}: \%$ & 33 \\
Unit weight, $\gamma: \mathrm{kN} / \mathrm{m}^{3}$ & $16 \cdot 9$ \\
Specific gravity, $G_{\mathrm{s}}$ & $2 \cdot 7$ \\
Organic content, OC: \% & $5-6$ \\
Overconsolidation ratio, OCR & $1-2$ \\
Angle of internal friction, $\phi^{\prime}:$ degrees & 31 \\
Undrained shear strength ratio, $s_{\mathrm{uc}} / \sigma_{\mathrm{v}}^{\prime}($ at $8 \mathrm{~m})$ & $0 \cdot 4$ \\
\hline
\end{tabular}

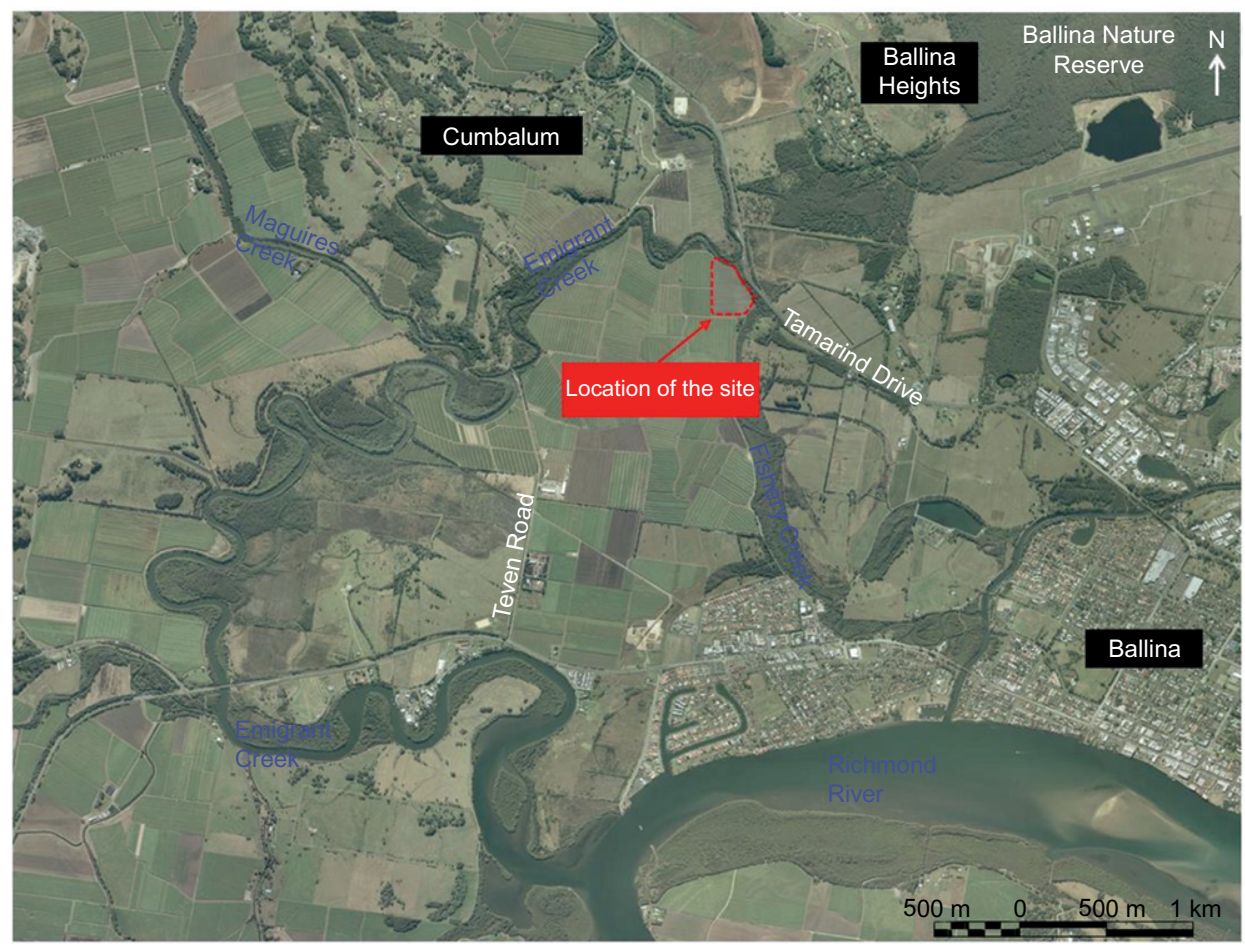

Fig. 1. Location of national soft soil field testing facility (Kelly et al., 2014) 


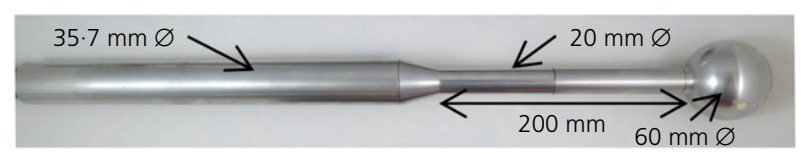

(a)

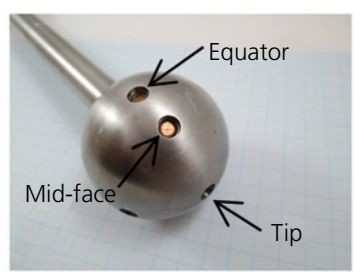

(b)

Fig. 2. Piezoball with pore pressure measurement locations at the equator, mid-face and tip

$55 \mathrm{~mm}$ above the sphere, which limits frictional resistance on the shaft contributing to the resistance measurements. Kyowa (PS-10KD) rear entry total pressure sensors with a measurement range of $\pm 1 \mathrm{MPa}$ were located in a circular recess on the surface of the sphere, such that the measurement diaphragm was $3 \mathrm{~mm}$ from the circumference. A $1.5 \mathrm{~mm}$ thick ceramic filter with a pore space of $10 \mu \mathrm{m}$ was located in front of (but not touching) each total pressure sensor. The piezoball features nine individual pore pressure sensors, four at the equator, four at the mid-face and one at the tip. The mid-face and equator pore pressure sensors were evenly spaced at each level, allowing assessment of the average pore pressure response for the mid-face and equator positions. Filters were saturated in the laboratory prior to field testing by submerging them in silicon oil in a container that was held under a vacuum of $100 \mathrm{kPa}$ for $24 \mathrm{~h}$ and were kept submerged in the oil until they were located on the piezoball. On site, the small voids between the sensing diaphragm of the total pressure sensor and the filter were filled with silicon oil before inserting the filters. The penetrometer was then submerged in a pressure chamber of silicon oil and cycles of positive and negative pressure were applied to the chamber for between 1 and $2 \mathrm{~h}$ prior to the test.

The testing campaign also included piezocone and T-bar tests, which were conducted to form a basis for comparing the penetration and pore pressure response. The piezocone has a diameter of $35.7 \mathrm{~mm}$ and an apex angle of $60^{\circ}$ with pore pressure measured at the $u_{2}$ position. T-bar tests were carried out by unscrewing the cone tip and replacing it with a cylindrical steel bar, $250 \mathrm{~mm}$ long and $40 \mathrm{~mm}$ in diameter, such that $A_{\mathrm{s}} / A_{\mathrm{p}}=0 \cdot 1$.

The penetrometer tests were conducted in two stages. The first stage focused on collecting a set of high-quality 'standard' piezocone, piezoball and T-bar penetration tests, conducted at the standard penetration velocity of $20 \mathrm{~mm} / \mathrm{s}$, including dissipation phases for both the piezocone and piezoball. These tests were achieved using a $20 \mathrm{t}$ commercial site investigation vehicle with conventional hydraulic systems for advancing the penetrometer. The second stage considered non-standard penetrometer test sequences involving variable penetration velocities. These tests employed a 2-t researchgrade site investigation vehicle with an electric drive system that permits complex actuation sequences, including penetration rates varying over three orders of magnitude and pauses that can either be in displacement or load control.

The data acquisition system (DAS) used with the penetrometers is based on the DAS developed for geotechnical centrifuge modelling at the University of Western Australia (Gaudin et al., 2009). The DAS is arranged on a long and narrow format circuit board that is located securely in the shaft of the penetrometer, just above the load cell. The DAS is capable of providing sensor excitation for up to 16 channels (necessary for the multiple pore pressure sensors) that may be sampled at up to $10 \mathrm{~Hz}$ at 16-bit resolution. Signal amplification, processing and filtering is carried out before the analogue to digital conversion. Data are then transmitted as a digital signal by way of RS232 to the soil surface, where it is converted to USB (universal serial bus) and plotted in real time on a computer or laptop and saved. In addition to the resistance and pressure measurements, temperature and inclination are also measured, allowing appropriate corrections to be applied if required.

\section{RESULTS AND DISCUSSION}

\section{Penetration tests}

Undrained penetration tests were carried out at the recommended rate of $20 \mathrm{~mm} / \mathrm{s}$ (Lunne et al., 1997). Fig. 3 shows typical resistance profiles for the different penetrometers for these undrained tests. Fig. 3(a) presents the net resistance, after correcting the measured resistance for pore pressure and overburden pressure effects according to

$$
q_{\mathrm{cnet}}=q-\left[\sigma_{\mathrm{v}}-u_{2}(1-\alpha)\right]
$$

for the piezocone (Lunne et al., 1997) and

$$
q_{\mathrm{bnet}} \text { or } q_{\mathrm{Tnet}}=q-\left[\sigma_{\mathrm{v}}-u_{0}(1-\alpha)\right] \frac{A_{\mathrm{s}}}{A_{\mathrm{p}}}
$$

for the piezoball and T-bar (Chung \& Randolph, 2004) where $q$ is the measured penetration resistance, $q_{\mathrm{cnet}}, q_{\mathrm{bnet}}$ and $q_{\text {Tnet }}$ are the net penetration resistances for the piezocone, piezoball and T-bar respectively, $\sigma_{\mathrm{v}}$ is the in situ vertical stress, $\alpha$ is the net area ratio and $u_{0}$ is the in situ hydrostatic pore pressure. As shown by Chung \& Randolph (2004), the correction required for the piezocone is generally higher than for the piezoball and T-bar. Here, the correction required for the piezocone varied between 20 and $40 \%$ in the estuarine clay layer, while the piezoball and T-bar correction remained below $10 \%$.

Once through the alluvium deposit at $1.5 \mathrm{~m}$, the net resistance increases linearly with depth with a gradient of approximately $10 \mathrm{kPa} / \mathrm{m}$ for both the piezoball and T-bar. The piezocone net resistance profile is also very close to that of the piezoball and T-bar, although $q_{\text {cnet }}$ is slightly lower than $q_{\text {bnet }}$ and $q_{\text {Tnet }}$ up to $4 \mathrm{~m}$ and is marginally higher beyond $8 \mathrm{~m}$. It is worth noting that the piezocone resistance required correction for temperature effects. The basis of this correction was to adjust the output from the load cell strain gauges to account for changes in temperature relative to the soil surface. The effect of change in temperature on the piezocone load cell strain gauge output was assessed in the laboratory prior to the field tests (Suzuki, 2015). A correction was then applied to the measured penetration test based on the measured profile of temperature with penetration depth. Applying this correction to the piezocone resistance resulted in a reduction of the measured resistance by up to $50 \%$. Although the T-bar tests were carried out with the same piezocone penetrometer (replacing the conical probe with the T-bar), the larger projected area resulted in minimal correction to the T-bar penetration resistance $(<3 \%)$. Similarly, the temperature effect on the piezoball penetration resistance was negligible. Spikes in the data at 4, 8, 10 and $12 \mathrm{~m}$ correspond to depths where dissipation tests were carried out.

Excess pore pressure profiles in Fig. 3 are based on the average of the four sensors at the equator and mid-face and the single sensor at the tip. There were slight variations among the measurements at each position, with coefficients of variation that were typically 0.04 for the mid-face position 


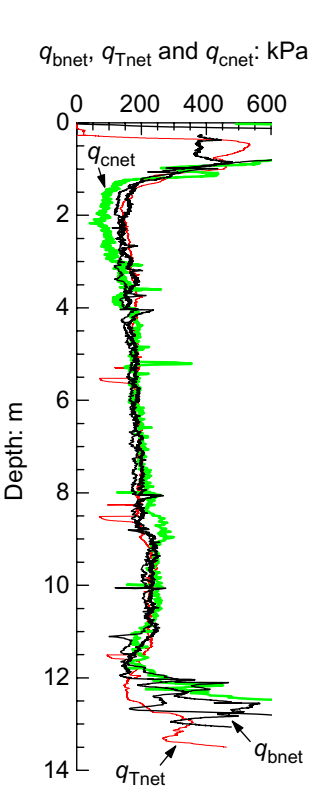

(a)

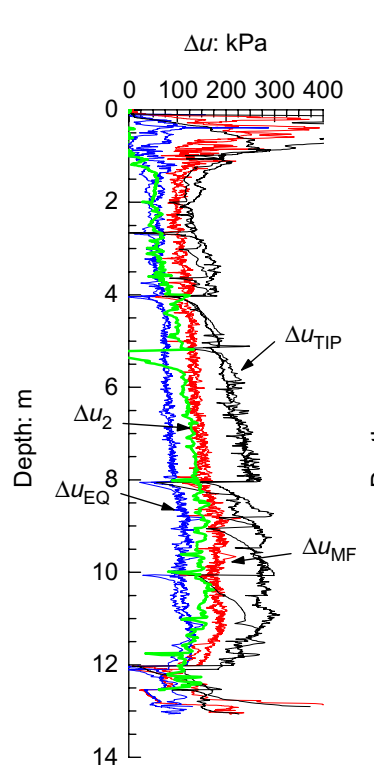

(b)

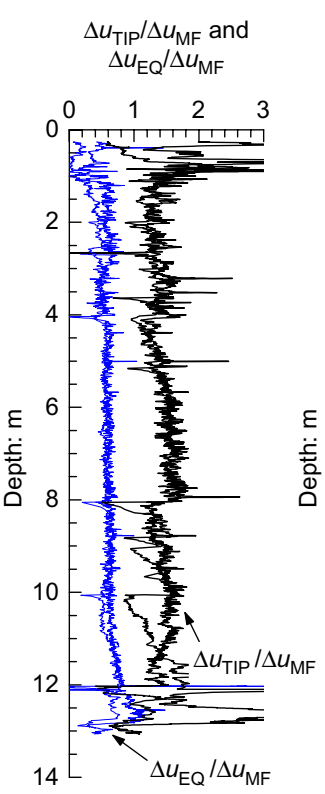

(c)

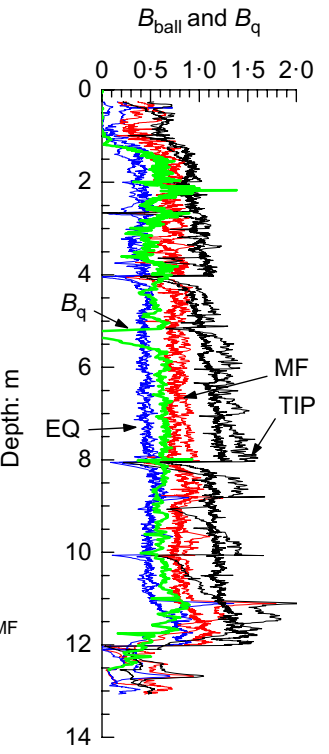

(d)

Fig. 3. Profiles of: (a) net penetration resistance; (b) excess pore pressure; (c) piezoball excess pore pressure ratios; (d) piezoball and piezocone pore pressure parameters

and $0 \cdot 12$ for the equator position. The excess pore pressures generated around the piezoball reflect the stress distribution (Boylan et al., 2010). At the tip, where compressive stresses are high, excess pore pressures are expected to be high. At the equator position, the soil is primarily subjected to pure shear, which will generate either positive or negative excess pore pressure depending on whether the soil exhibits contractive or dilative behaviour. At the mid-face position, the stresses are a combination of compression and shear, such that the magnitude of the excess pore pressure should lie between those at the tip and equator. This is confirmed by Fig. 3(b), which compares excess pore pressures generated around the piezoball and piezocone.

The excess pore pressure measured by the piezocone at the $u_{2}$ position is closest to (but lower than) the excess pore pressure at the piezoball mid-face position, similar to findings from centrifuge studies (e.g. Mahmoodzadeh \& Randolph, 2014; Colreavy et al., 2015), although between 0 and $6 \mathrm{~m}, \Delta u_{2}$ is much lower. The excess pore pressure increase with depth is largest at the tip $(18 \mathrm{kPa} / \mathrm{m})$, lower at the mid-face $(10 \mathrm{kPa} / \mathrm{m})$ and lowest at the equator $(5 \mathrm{kPa} / \mathrm{m})$. After the pauses in penetration for the dissipations at 4,8 , 10 and $12 \mathrm{~m}$, further penetration of approximately six ball diameters is required for the equator and mid-face to reach steady-state conditions compared with over 12 diameters for the tip. Short pauses for rod changes caused a reduction in excess pore pressure measured at the tip but not at the mid-face or equator. Fig. 3(c) shows the ratio of the equator and tip excess pore pressure relative to those at the mid-face remain reasonably constant with depth, with values of $\Delta u_{\mathrm{EQ}} / \Delta u_{\mathrm{MF}} \approx 0.5$ and $\Delta u_{\mathrm{TIP}} / \Delta u_{\mathrm{MF}}$ varying between $1 \cdot 3$ and $1 \cdot 7$, with an average of $1 \cdot 5$. These values are consistent with previous findings; Colreavy et al. (2015) measured $\Delta u_{\mathrm{EQ}} / \Delta u_{\mathrm{MF}}=0.56$ to 0.6 in centrifuge tests on normally consolidated kaolin clay, whereas Mahmoodzadeh et al. (2015) reported similar relative magnitudes of excess pore pressure around the piezoball through large-deformation finite-element (LDFE) analysis of a ball penetrating into clay.

The piezocone pore pressure parameter, $B_{\mathrm{q}}=\Delta u_{2} / q_{\mathrm{cnet}}$, is a useful parameter for classifying soil behaviour type
(Robertson, 1990). Analogous pore pressure parameters for the piezoball can similarly be expressed as $B_{\text {ball }}=\Delta u_{\text {ball }} / q_{\text {bnet }}$. Fig. 3(d) shows that $B_{\mathrm{q}}$ and $B_{\text {ball }}$ at the mid-face and equator positions remain relatively constant with depth. $B_{\text {ball }}$ at the equator position is on average 0.5 , which is reasonably consistent with (an equator) $B_{\text {ball }}=0 \cdot 3$ to 0.4 as reported in field and centrifuge studies in soft clay (DeJong et al., 2008; Colreavy et al., 2012, 2015), but much higher than $B_{\text {ball }}=0 \cdot 1$ reported in field tests by Boylan et al. (2010). $B_{\text {ball }}$ at the mid-face position is approximately $0 \cdot 8$, slightly higher than (a mid-face) $B_{\text {ball }}=0.65$ as measured in centrifuge tests in normally consolidated clay (Colreavy et al., 2015). $B_{\text {ball }}$ at the tip ranges from 0.9 at $1 \mathrm{~m}$ to 1.25 at $11 \mathrm{~m}$, slightly higher than a (tip position) $B_{\text {ball }}=0.9$ in field tests reported by Boylan et al. (2010). As indicated by the net penetration resistance and excess pore pressure profiles, $B_{\mathrm{q}}$ is similar to, although slightly lower than, $B_{\text {ball }}$ at the mid-face position.

In many cases the tip sensor became unresponsive to changes in penetration depth due to clogging of the filter. This is despite submerging the piezoball in a pressure chamber of silicon oil and applying cycles of negative and positive pressure in the chamber for several hours between tests in an attempt to unclog and saturate the filters. Given that the pore pressure measured at the tip mainly reflects total stress changes, and the tendency for the filter to become clogged, the tip position provides limited insight during a piezoball test and is not considered further in the paper.

\section{Dissipation tests}

Piezoball and piezocone dissipation tests were carried out at various depths by pausing the penetration and allowing the excess pore pressure to dissipate. Fig. 4(a) compares the excess pore pressure response with time, $t$, for the piezoball and piezocone tests at $4 \mathrm{~m}$ depth following penetration at the standard $20 \mathrm{~mm} / \mathrm{s}$. Although the excess pore pressure, $\Delta u$, measured at the mid-face on the piezoball decays monotonically after $t=0, \Delta u$ measured at the piezoball equator position and at the piezocone $u_{2}$ position rise over the first $20 \mathrm{~s}$ before starting to decay. This response is commonly observed and, although it is often attributed to poor filter 


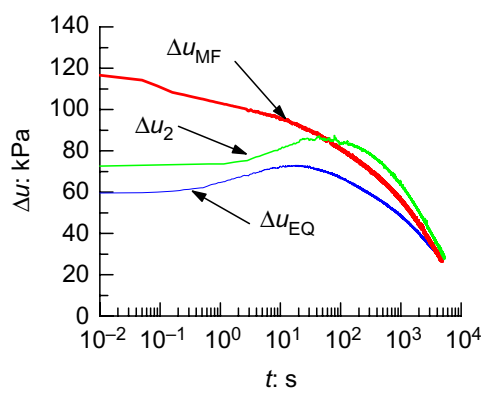

(a)

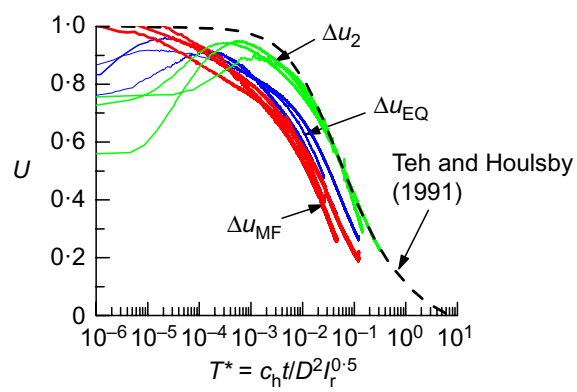

(b)

Fig. 4. Piezoball and piezocone dissipation curves at a depth of $4 \mathbf{m}$ shown in: (a) actual time; (b) 'consolidation time'

saturation, it is now considered to reflect redistribution of pore pressures from the face to the shoulder of the cone and around the circumference of the ball (Chai et al., 2012; Mahmoodzadeh et al., 2015).

The same data are replotted in normalised form in Fig. 4(b), including data from other depths, with consolidation time, $T$, defined as (Teh \& Houlsby, 1991)

$$
T^{*}=\frac{c_{\mathrm{h}} t}{D_{\mathrm{c}}^{2} I_{\mathrm{r}}^{0.5}}
$$

where $t$ is the dissipation time and $D_{\mathrm{c}}$ is the piezocone diameter. The rigidity index, $I_{\mathrm{r}}=G / s_{\mathrm{u}}$, where $G$ is the shear modulus and $s_{\mathrm{u}}$ is the undrained shear strength, was calculated as 80 using $G$ estimated from the unload-reload stress-strain response from pressuremeter tests and $s_{\mathrm{u}}$ from the penetration resistance using a bearing factor, $N=11.9$ (Kelly et al., 2014). The relatively small strain range from pressuremeter unload-reload curves yields a shear modulus that is considered appropriate for back-analysis of the dissipation responses, which will involve very small shear strains within the soil. The excess pore pressure is normalised as $U=\Delta u / \Delta u_{\mathrm{i}}$, where $\Delta u_{\mathrm{i}}$ is the initial excess pore pressure. To account for the initial redistribution of pore pressures, $\Delta u_{\mathrm{i}}$ at $t=0$ was estimated using the root time extrapolation method (Sully et al., 1999). This method accounts for redistribution of pore pressure around the ball before dissipation, although for the mid-face position $\Delta u_{\mathrm{i}}$ calculated using this approach gave very similar values to the measured value at $t=0$. Also shown on Fig. 4(b) is the Teh \& Houlsby (1991) theoretical solution, which provided a basis for determining $c_{\mathrm{h}}$ by obtaining the best match between the piezocone $u_{2}$ excess pore pressure response and the theoretical curve. This resulted in $c_{\mathrm{h}}=0.3 \mathrm{~mm}^{2} / \mathrm{s}$ at $4 \mathrm{~m}$, reducing to approximately $c_{\mathrm{h}}=0.08 \mathrm{~mm}^{2} / \mathrm{s}$ between 8 and $10 \mathrm{~m}$, before increasing to $c_{\mathrm{h}}=5.3 \mathrm{~mm}^{2} / \mathrm{s}$ at $12 \mathrm{~m}$, reflecting the vicinity of the sand layer (see Table 2). Rowe cell tests conducted on samples retrieved from a depth of $8 \mathrm{~m}$ gave $c_{\mathrm{v}}=0.14 \mathrm{~mm}^{2} / \mathrm{s}$ at the in situ vertical effective stress (with estimated yield stress ratio of $1 \cdot 5)$, similar to $c_{\mathrm{h}}=0.08 \mathrm{~mm}^{2} / \mathrm{s}$ from the piezocone dissipation tests between 8 and $10 \mathrm{~m}$.
Table 2. Coefficient of horizontal consolidation values deduced from piezocone and piezoball dissipation tests

\begin{tabular}{l|c|c|c}
\hline \multirow{2}{*}{ Depth: m } & \multicolumn{3}{|c}{$c_{\mathrm{h}}: \mathrm{mm}^{2} / \mathrm{s}$} \\
\cline { 2 - 4 } & $u_{2}$ & $u_{\mathrm{MF}}$ & $u_{\mathrm{EQ}}$ \\
\hline 4 & $0 \cdot 31$ & $0 \cdot 33$ & 0.33 \\
8 & $0 \cdot 08$ & 0.06 & 0.05 \\
10 & 0.07 & 0.06 & 0.04 \\
12 & $5 \cdot 32$ & & \\
\hline
\end{tabular}

The non-dimensional time for $50 \%$ excess pore pressure dissipation for the piezoball mid-face is $3 \cdot 2$ to 5 times lower than for the piezocone, with the upper limit consistent with centrifuge results reported by Colreavy et al. (2015). Dissipation was also faster at the piezoball equator position than at the $u_{2}$ position of the piezocone, by a ratio of 2 to 3 compared with 1.5 in the centrifuge tests reported by Colreavy et al. (2015). In absolute measure of time, excess pore pressures dissipated $1 \cdot 1$ to $1 \cdot 4$ times faster at the piezoball mid-face compared with the piezocone. Excess pore pressure dissipation at the piezoball equator takes a similar or slightly longer time than for the piezocone by a factor of between 1.0 and 1.4 . This observation, which has also been noted in centrifuge tests reported by Mahmoodzadeh \& Randolph (2014) and Colreavy et al. (2015), is noteworthy as the piezoball diameter $(60 \mathrm{~mm})$ is 1.7 times higher than the piezocone diameter $(35.7 \mathrm{~mm})$. The faster dissipation for the piezoball is due to a combination of the smaller volume of soil involved in the failure mechanism around an advancing piezoball, and the higher excess pore pressure gradient around the piezoball (Low et al., 2007).

Interpretation of piezocone dissipation tests is complicated as the Teh \& Houlsby (1991) solution does not allow independent assessment of $c_{\mathrm{h}}$ and $I_{\mathrm{r}}$ (Mahmoodzadeh \& Randolph, 2014; Mahmoodzadeh et al., 2014). As shown by Lu et al. (2000), the penetration of an ideal ball (with no shaft) is independent of $I_{\mathrm{r}}$. However, in an actual piezoball dissipation test, excess pore pressure from cavity expansion around the shaft will contribute to the excess pore pressure measured at the circumference of the ball. Mahmoodzadeh et al. (2015) reported LDFE analyses of dissipation around shafted balls of various diameter ratios and showed that a unique response was obtained by normalising the dissipation time as

$$
T_{\mathrm{b}}=\frac{c_{\mathrm{h}} t}{D_{\mathrm{b}} d I_{\mathrm{r}}^{0 \cdot 25}}
$$

where $D_{\mathrm{b}}$ and $d$ are the piezoball sphere and shaft diameters, respectively. Note that the rigidity index still contributes to the normalised dissipation time but the influence is muted compared with the piezocone. Mahmoodzadeh et al. (2015) combined their results and developed a unique dissipation piezoball profile for both the mid-face and equator positions which can be fitted (for $U<0 \cdot 7$ ) by

$$
U=\frac{\Delta u}{\Delta u_{\mathrm{i}}} \approx \frac{1}{1+T_{\mathrm{b}} / T_{\mathrm{b} 50}}
$$

where $T_{\mathrm{b} 50}$, the non-dimensional time for $50 \%$ dissipation, is $0 \cdot 12$ and $0 \cdot 18$ for the mid-face and equator positions, respectively.

Measured piezoball dissipation curves from 4, 8 and $10 \mathrm{~m}$ depths are compared to the Mahmoodzadeh et al. (2015) LDFE solutions in Fig. 5, adjusting $c_{\mathrm{h}}$ such that the measured mid-face dissipation curve and the LDFE curve coincide at $T_{\mathrm{b} 50}$. Although the gradient of the measured curve does not match the LDFE curve very well, $c_{\mathrm{h}}$ from this 
matching process is in the range of 0.75 to 1.06 times that from the piezocone, with an average of 0.9 . The same process for the equator position results in $c_{\mathrm{h}}$ values that are up to 1.5 times lower than the mid-face values (see Table 2).

\section{Effects of penetration rate}

Penetration resistance and excess pore pressure. Piezoball resistance will be affected by the penetration rate, $v$, the piezoball diameter, $D_{\mathrm{b}}$, and the coefficient of consolidation, $c_{\mathrm{v}}$ or $c_{\mathrm{h}}$, combined to give normalised velocities of (Finnie \& Randolph, 1994)

$$
V=\frac{v D_{\mathrm{b}}}{c_{\mathrm{v}}} \quad \text { or } \quad V^{\prime}=\frac{v D_{\mathrm{b}}}{c_{\mathrm{h}}}
$$

Although the former quantity $V$, based on $c_{\mathrm{v}}$, was used in earlier studies (e.g. House et al., 2001; Low et al., 2008), because consolidation during penetration is controlled by the same process as during a dissipation test, it is more logical to use $V^{\prime}$, based on $c_{\mathrm{h}}$, to quantify partial consolidation (Lehane et al., 2009; Mahmoodzadeh et al., 2014, 2015; Colreavy et al., 2015).

Several researchers have studied the dependence of penetration velocity on penetrometer resistance (e.g. Bemben \& Myers, 1974; Roy et al., 1982; House et al., 2001; Chung et al., 2006; Lehane et al., 2009; Mahmoodzadeh \& Randolph, 2014). When penetrating at a high velocity in low-permeability soil, a reduction in velocity will result in a reduction in penetrometer resistance due to a decrease in the viscous influence of strain rates. This results in a minimum penetrometer resistance when the velocities are still sufficiently high to limit partial consolidation, but with reduced

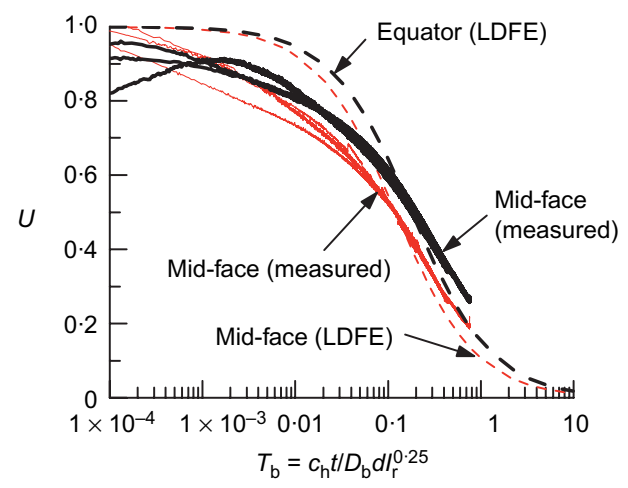

Fig. 5. Comparison of piezoball dissipation curves with Mahmoodzadeh et al. (2015) numerical solution additional resistance due to strain rate effects. Further reduction in the penetration velocity will cause an increase in penetrometer resistance due to partial consolidation, reducing the magnitude of excess pore pressure and increasing soil strength locally, eventually reaching a steady drained resistance.

In addition to the constant rate of penetration tests, piezoball twitch tests were also conducted in which the penetration velocity was successively reduced over a number of depth intervals. A typical piezoball twitch test result is shown in Fig. 6. Twitch tests were carried out at penetration velocities in the range $v=20$ down to $0.02 \mathrm{~mm} / \mathrm{s}$ (i.e. varying over three orders of magnitude), with each velocity maintained for at least $250 \mathrm{~mm}\left(4 \cdot 2 D_{\mathrm{b}}\right)$ to ensure steady-state conditions were achieved. Twitch test results for depth intervals 3 to $4 \mathrm{~m}$ and 6 to $7 \mathrm{~m}$ are shown in Fig. 7. The data are presented as net penetration resistance normalised by the net penetration resistance at $20 \mathrm{~mm} / \mathrm{s}, q_{\text {bnet }} / q_{\text {bnet(ref), }}$, against the non-dimensional velocity (equation (6)) using $c_{\mathrm{h}}$ estimated from the piezoball mid-face dissipation tests, following penetration at $20 \mathrm{~mm} / \mathrm{s}$. The data in Fig. 7 follow the pattern described previously, although the lowest penetration velocity $(0.02 \mathrm{~mm} / \mathrm{s})$ is insufficiently slow to generate a drained response, and appears to indicate the onset of partial drainage. Also shown in Fig. 7(a) is a backbone curve describing the expected evolution of $q_{\text {bnet }} / q_{\text {bnet(ref) }}$ with $V^{\prime}$, combining viscous effects in the undrained region and partial consolidation and undrained regions (Randolph \& Hope, 2004)

$$
\begin{aligned}
\frac{q_{\text {bnet }}}{q_{\text {bnet }(\mathrm{ref})}}= & \left(1+\frac{b}{1+\left(V^{\prime} / V_{50}^{\prime}\right)^{d}}\right) \\
& \times\left\{\frac{1+(\mu / \ln (10))\left[\sinh ^{-1}\left(V^{\prime} / V_{0}^{\prime}\right)\right]}{1+(\mu / \ln (10))\left[\sinh ^{-1}\left(V_{\text {ref }}^{\prime} / V_{0}^{\prime}\right)\right]}\right\}
\end{aligned}
$$

where $b$ and $d$ are fitting constants, $V_{50}^{\prime}$ corresponds to a penetration resistance that is an average of undrained and drained values, $\mu$ is a strain-rate parameter and $V_{0}^{\prime}$ is the rate at which strain-rate effects start to decay to zero. $V_{\text {ref }}^{\prime}$ is the reference normalised velocity and ideally should be taken as that corresponding to the minimum resistance value, although it is often (as is the case here) taken as the normalised velocity corresponding to $v=20 \mathrm{~mm} / \mathrm{s}$. The first bracketed term describes the partially drained response, while the second bracketed term captures strain-rate effects. The lack of resistance data in the partially drained region may support a reduced form of equation (7), limited to the second bracketed term. However, as will be shown later, the excess pore pressure provides stronger indications of partial

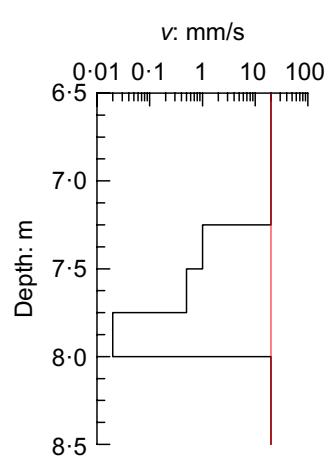

(a)

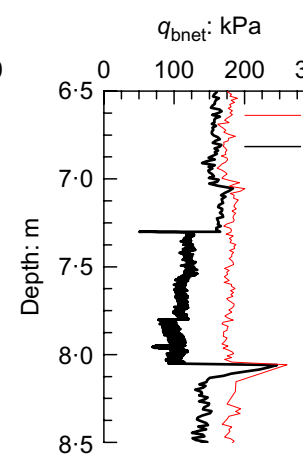

(b)

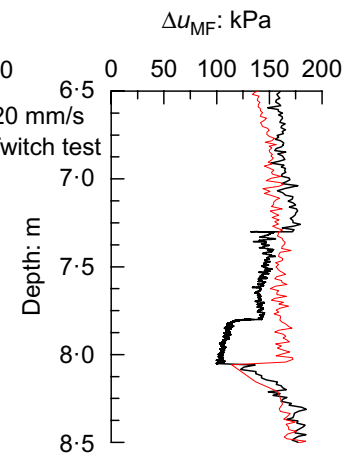

(c)

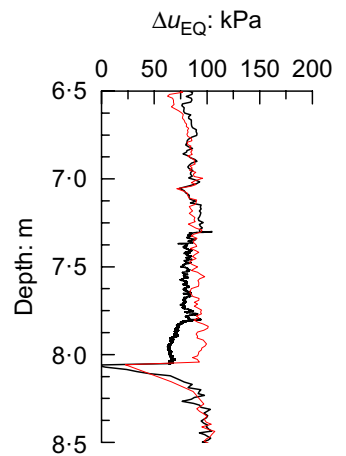

(d)

Fig. 6. Example of piezoball twitch test results compared with standard constant penetration velocity test: (a) velocity; (b) net penetration resistance; (c) excess pore pressure at mid-face position; (d) excess pore pressure at equator position 


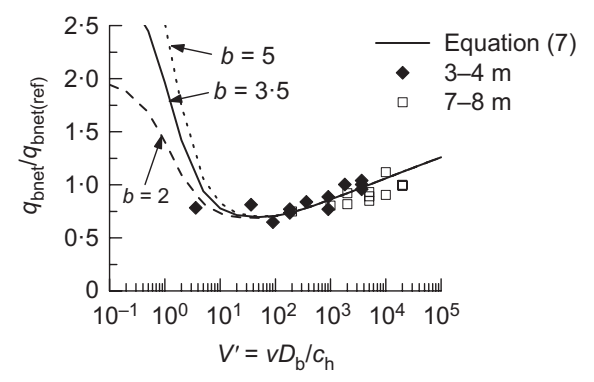

(a)

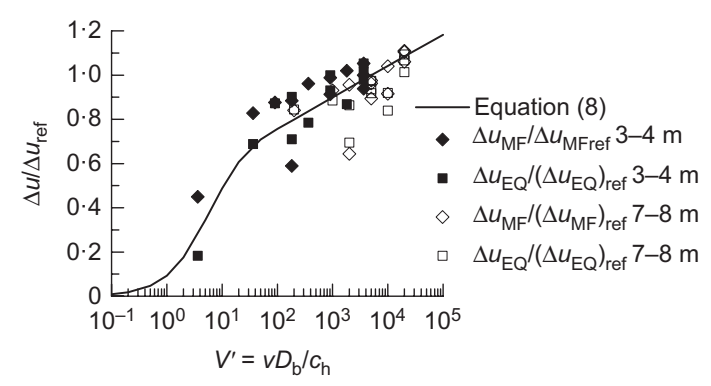

(b)

Fig. 7. Piezoball backbone curves of: (a) net penetration resistance; (b) excess pore pressure

drainage at the lower penetration velocities, justifying the use of the complete form of equation (7). The best fit to the data was obtained using $\mu=0 \cdot 2$ and $V_{0}^{\prime}=200$ for viscous effects, whereas the partially drained region was described using $b=3 \cdot 5, d=1 \cdot 4$ and $V_{50}^{\prime}=1 \cdot 2$ (Colreavy et al., 2015). Alternative versions of equation (7) using $b=2$ and 5 do not affect the fit to the data in the viscous region where strain rates dominate. The parameter list used to generate the backbone curves in Fig. 7 is summarised in Table 3. The transition from a partially drained to fully undrained response occurs at approximately $V^{\prime}=30$, consistent with previous findings for T-bar, cone and ball penetrometers (Randolph \& Hope, 2004; Chung et al., 2006; Lehane et al., 2009; Jaeger et al., 2010; Mahmoodzadeh \& Randolph, 2014; Colreavy et al., 2015). An important observation from Fig. 7(a) is that the standard penetration velocity, $v=20 \mathrm{~mm} / \mathrm{s}$, is over two orders of magnitude higher than the minimum penetration velocity required for undrained conditions. This results in a net penetration resistance, and hence a derived undrained shear strength, that will be approximately $40 \%$ higher than the minimum (arguably a 'true' rate-independent and essentially undrained) value. The observations made here are for a piezoball penetrometer, but will also apply to other penetrometers including the piezocone, provided that the strain rates, which may be approximated by $v / D$, are similar (to an order of magnitude).

The evolution of excess pore pressure with changing penetration rate is shown in Fig. 7(b). As with the penetration resistance data, a reduction in penetration rate causes a reduction in excess pore pressure associated with reductions in total stress. Below $V^{\prime}=30$, the reduction in $\Delta u$ is more marked, as the response moves into the partially drained range where less pore pressure is generated during penetration. As with the penetration resistance, the normalised excess pore pressure in Fig. 7(b) can be fitted by a backbone curve

$$
\begin{aligned}
\frac{\Delta u}{\Delta u_{\mathrm{ref}}}=1 & -\frac{1}{1+\left(V^{\prime} / V_{50, \Delta u}^{\prime}\right)^{f}} \\
& \times\left\{\frac{1+(\mu / \ln (10))\left[\sinh ^{-1}\left(V^{\prime} / V_{0}^{\prime}\right)\right]}{1+(\mu / \ln (10))\left[\sinh ^{-1}\left(V_{\mathrm{ref}}^{\prime} / V_{0}^{\prime}\right]\right.}\right\}
\end{aligned}
$$

Table 3. Backbone curve-fitting parameters

\begin{tabular}{l|c|c|l|c|l|l}
\hline Parameter & $b$ & $d, f$ & $V_{50}^{\prime}$ & $\mu$ & $V_{0}^{\prime}$ & $V_{\text {ref }}^{\prime}$ \\
\hline$q_{\mathrm{bnet}}$ & $3 \cdot 5$ & $1 \cdot 4$ & $1 \cdot 2$ & $0 \cdot 20$ & 200 & 5000 \\
$\Delta u_{\mathrm{MF}}$ and $\Delta u_{\mathrm{EQ}}$ & - & $1 \cdot 1$ & 6 & $0 \cdot 14$ & 200 & 5000 \\
\hline
\end{tabular}

where $f$ is a fitting parameter (similar to $d$ in equation (7)). The best fit between the measured data and equation (8) was obtained using $f=1 \cdot 1, V_{50, \Delta u}^{\prime}=6, \mu=0 \cdot 14$ and the same $V_{\text {ref }}^{\prime}=5000$ and $V_{0}^{\prime}=200$ used with equation (7). However, given the paucity of data in the partial consolidation region, the value of $V_{50, \Delta u}^{\prime}$ is somewhat uncertain, and indeed is rather higher than the value of 0.9 observed by Mahmoodzadeh \& Randolph (2014), with more extensive data in the partial consolidation range. The lower $f$ in equation (8) relative to $d$ in equation (7) implies that the excess pore pressure is less affected by changes in penetration rate than the penetration resistance, while the higher $V_{50, \Delta u}^{\prime}$ suggests that the excess pore pressure begins to show a partially drained response at higher penetration rates than the penetration resistance. At the lowest penetration velocity the normalised excess pore pressure reaches as low as $\Delta u / \Delta u_{\text {ref }}=0.2$ and 0.65 at 4 and $8 \mathrm{~m}$, respectively, while the normalised penetration resistance at the same penetration velocity is almost identical to the undrained value. The lower strain rate parameter, $\mu=0 \cdot 14$, implies that $\Delta u$ increases at a lower rate than $q$ in the viscous range, perhaps because, at high strain rates, a degree of turbulent shearing introduces a slightly dilative response, reducing $\Delta u$ relative to $q$.

Dissipation tests. As shown earlier, the overall fit between the measured piezoball dissipation test after a penetration rate of $20 \mathrm{~mm} / \mathrm{s}$ and the LDFE solution was quite poor. However, as shown by Fig. 7, at $v=20 \mathrm{~mm} / \mathrm{s}$ the penetration is over two orders of magnitude into the viscous range, causing an extra component in the excess pore pressure. This distorts the shape of subsequent dissipation profiles.

Several additional piezoball dissipation tests were carried out following the reduced penetration velocities during twitch tests. Fig. 8 shows comparisons between the LDFE solutions and the piezoball dissipation responses following penetration at each of the four velocities involved at the end of each twitch test, where the dissipation times are normalised using $c_{\mathrm{h}}$ estimated from the piezocone dissipation tests following penetration at $v=20 \mathrm{~mm} / \mathrm{s}$. The figure shows that, although the back-calculated $c_{\mathrm{h}}$ does not vary significantly for each penetration velocity when $T_{\mathrm{b} 50}$ is matched to the LDFE solution, the match in the overall response improves as the penetration velocity reduces, with the best fit obtained for the mid-face position at a penetration rate $v=0.02 \mathrm{~mm} / \mathrm{s}$. This penetration velocity corresponds with $V^{\prime}=4(4 \mathrm{~m})$ and $20(8 \mathrm{~m})$, where strain rate effects are least pronounced. As the numerical solution does not account for viscous strain rate effects, it would be useful to explore, numerically, whether adding strain-rate dependency to the soil model might change either the shape of the dissipation response or the value of $T_{\mathrm{b} 50}$.

Although the equator dissipation profiles match the LDFE curve reasonably well following penetration at $v=0.02 \mathrm{~mm} / \mathrm{s}$, the fit is slightly better following penetration at $v=0.2 \mathrm{~mm} / \mathrm{s}$. As noted by Mahmoodzadeh et al. (2015), however, the LDFE fits for dissipation at the equator tend to underestimate the timescale of dissipation compared with experimental data. 

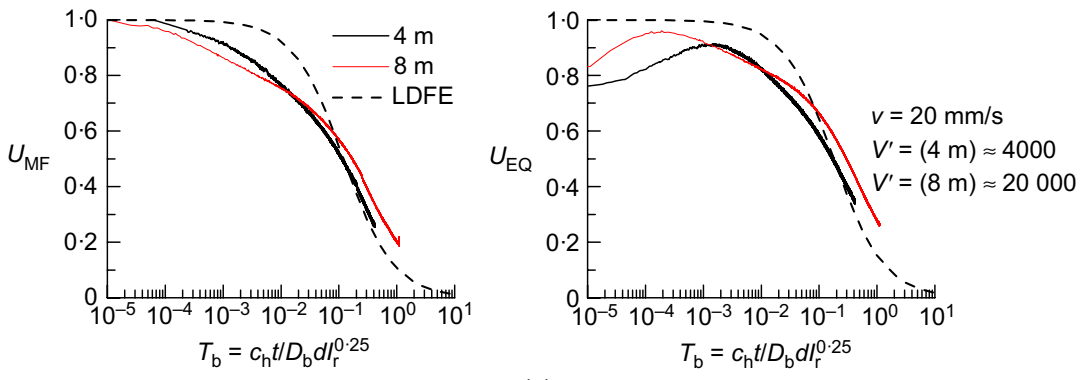

(a)
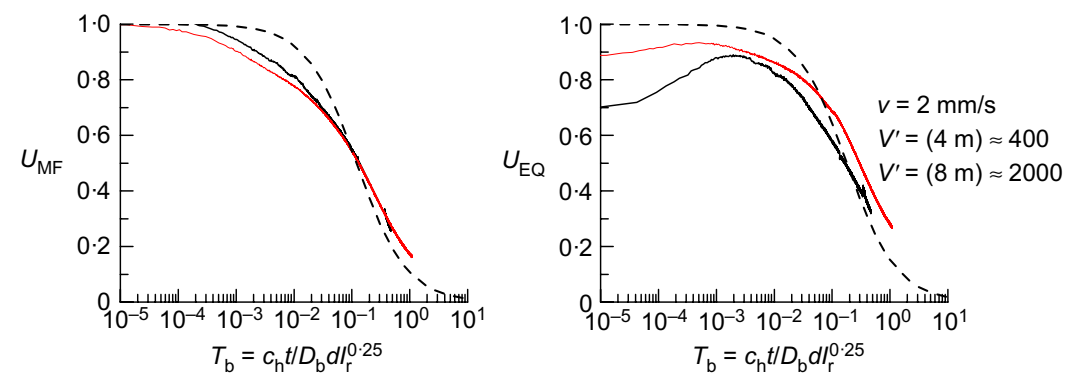

(b)
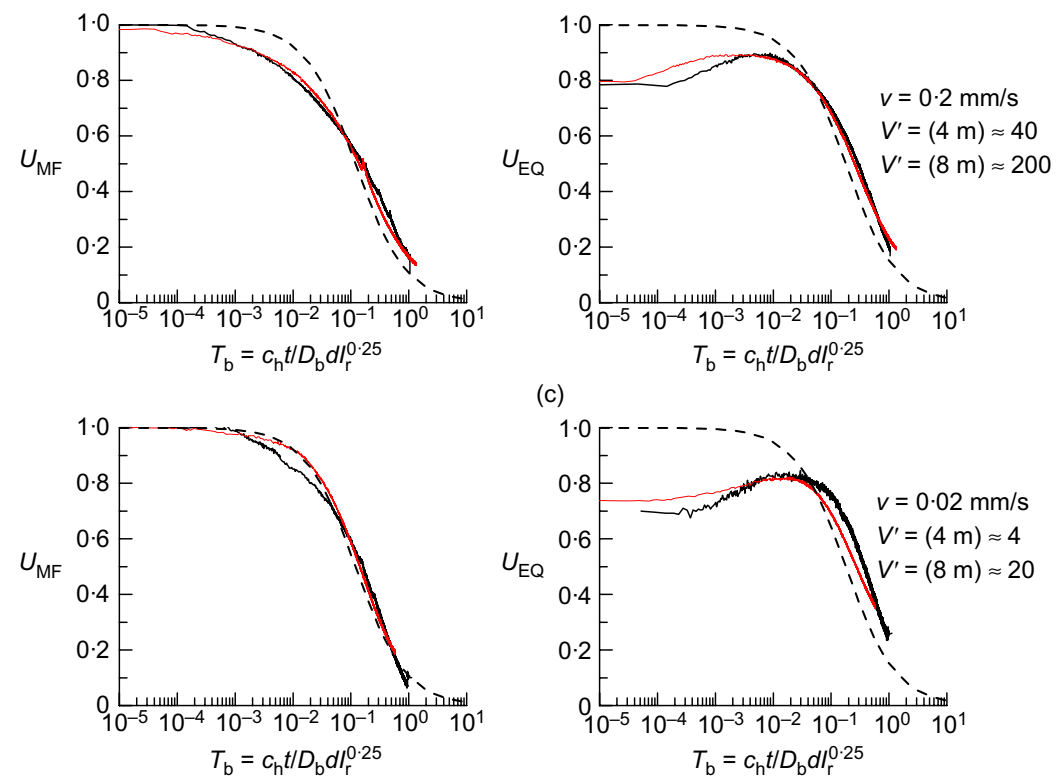

(d)

Fig. 8. Measured and numerical excess pore pressure dissipation responses following penetration at: (a) $20 \mathrm{~mm} / \mathrm{s} ;($ b) $2 \mathrm{~mm} / \mathrm{s} ;($ c) $0 \cdot 2 \mathrm{~mm} / \mathrm{s}$; (d) $0.02 \mathrm{~mm} / \mathrm{s}$

Partial consolidation indicators. Colreavy et al. (2015) demonstrated that when partial consolidation occurs during a piezoball penetration phase, $c_{\mathrm{h}}$ may be underestimated by a factor of over six in a subsequent dissipation test. Analysis of the data considered here shows that although penetration velocities in excess of that required for an undrained response do not unduly affect the back-calculated coefficient of consolidation, the overall fit between the dissipation profile and that observed following nominally undrained penetration is poorer, which may hamper the back-analysis to determine $c_{\mathrm{h}}$. Additionally, as shown earlier in the paper, the standard penetration velocity, $v=20 \mathrm{~mm} / \mathrm{s}$, may overestimate the soil strength deduced from the net penetration resistance, depending on the consolidation characteristics of the soil. For these reasons it would be advantageous to have a means of assessing the drainage conditions during a penetration test.

It is evident from Fig. 8 that the time taken for the equator excess pore pressure to reach a maximum, $t_{\max }$, generally increases as the penetration response moves gradually towards the region of partial consolidation, consistent with observations by Mahmoodzadeh \& Randolph (2014) and Colreavy et al. (2015).

Mahmoodzadeh \& Randolph (2014) also showed that the ratio between the initial and maximum equator excess pore pressure, $\Delta u_{\mathrm{i}} / \Delta u_{\max }$ varied with drainage conditions. Fig. 8 suggests that this ratio remains relatively constant for $V^{\prime}=4$ to 20000 , although consideration of data presented by Mahmoodzadeh \& Randolph (2014) suggests that $\Delta u_{\mathrm{i}} / \Delta u_{\max }$ reduces at $V^{\prime}<3$. However, as this is an order of magnitude lower than that required for undrained conditions, $\Delta u_{\mathrm{i}} / \Delta u_{\max }$ is not considered a reliable indicator of partial consolidation.

Colreavy et al. (2015) demonstrated that $B_{\text {ball }}$ is a useful indicator of partial consolidation. Fig. 9 compares $B_{\text {ball }}$ at different $V^{\prime}$ from the field tests considered here together with centrifuge data reported by Mahmoodzadeh \& Randolph (2014) and Colreavy et al. (2015). Although the data for the equator position are somewhat scattered, collectively they 
show that $B_{\text {ball }}$ is highest at a normalised velocity $V^{\prime}=30$ (near the point of minimum penetration resistance), with values of $B_{\text {ball }}=0.9$ and 0.5 for the mid-face and equator positions, respectively. As $V^{\prime}$ reduces, $B_{\text {ball }}$ for both the equator and mid-face positions tends towards zero as the response becomes drained. In the viscous penetration range $\left(V^{\prime}>30\right)$ there is a slight reduction in $B_{\text {ball }}$, which reflects $q_{\text {bnet }}$ increasing at a higher rate than the excess pore pressure (as also shown in Fig. 7). Fig. 9 supports the potential for $B_{\text {ball }}$ as a strong indicator for partial consolidation during penetration.

\section{ESTIMATION OF $C_{\mathrm{h}}$ FROM PIEZOBALL DISSIPATION TESTS}

In this section an alternative empirical method for estimating $c_{\mathrm{h}}$ from piezoball dissipation test data is outlined and compared with a database of field and centrifuge piezoball dissipation records. The database includes four field sites and two separate centrifuge studies on kaolin clay.

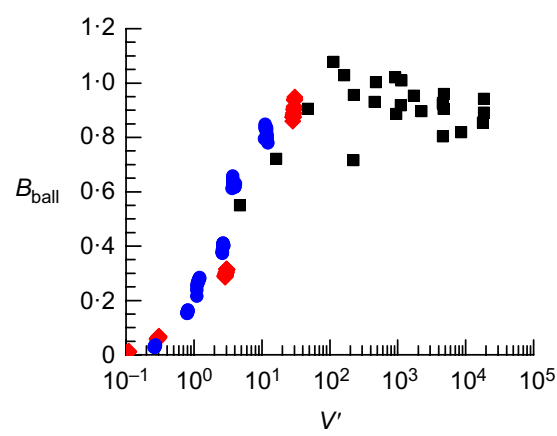

(a)

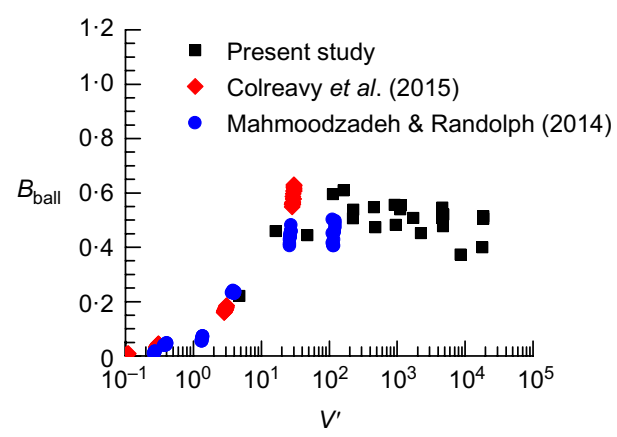

(b)

Fig. 9. $B_{\text {ball }}$ as a partial consolidation indicator: (a) mid-face; (b) equator
The baseline measure of $c_{\mathrm{h}}$ for each case was by interpretation of piezocone dissipation tests using the Teh \& Houlsby (1991) solution.

As shown by Fig. 4 and Fig. 8, the excess pore pressure dissipation profile at the piezoball equator location is characterised by an initial rise in excess pore pressure before decaying towards zero. The time for $50 \%$ excess pore pressure dissipation at the equator position, $t_{50, \mathrm{EQ}}$, increases as penetration moves further into the partially drained range (Colreavy et al., 2015), whereas at penetration velocities in excess of that required for nominally undrained conditions, $t_{50 \text {,EQ }}$ remains approximately constant. Meanwhile, the time required to reach the maximum excess pore pressure, $t_{\max }$, will increase with increasing penetration velocity in both the partially drained (Mahmoodzadeh \& Randolph, 2014) and undrained range (this study). Fig. 10 plots $t_{\max }$ as the non-dimensional time, $T_{\max }=c_{\mathrm{h}} t_{\max } / D_{\mathrm{b}} d I_{\mathrm{r}}^{0 \cdot 25}$, against the $t_{\max } / t_{50}$ ratio for each site. The data on Fig. 10 include dissipations following a range of penetration velocities, spanning the partially drained to viscous-undrained range and can be described by the following power function

$$
c_{\mathrm{h}}=0.7\left(\frac{D_{\mathrm{b}} d I_{\mathrm{r}}^{0.25}}{t_{\max }}\right)\left(\frac{t_{\max }}{t_{50}}\right)^{1 \cdot 2}
$$

The merit of the empirical method can be assessed from Fig. 11, which compares $c_{\mathrm{h}}$ values estimated from equation (9) with $c_{\mathrm{h}}$ values determined from piezocone dissipation tests. The agreement in predicted $c_{\mathrm{h}}$ is within better than an order of magnitude for the entire dataset, which spans three orders of magnitude variation in $c_{\mathrm{h}}$. Equation (9) overestimates $c_{\mathrm{h}}$ by on average $10 \%$, which is within the range demonstrated earlier in the paper in the estimation of $c_{\mathrm{h}}$ using the Mahmoodzadeh et al. (2015) LDFE solution.

\section{CONCLUDING REMARKS}

The coefficient of consolidation is an important property for the design of geotechnical structures. Often the most reliable method of assessing $c_{\mathrm{h}}$ is through in situ dissipation tests, particularly offshore. Although piezocone dissipation tests are a proven method of assessing $c_{\mathrm{h}}$, experimental evidence -including that presented here-shows that excess pore pressure may dissipate more quickly around a piezoball than a piezocone, and that $c_{\mathrm{h}}$ may be calculated from the dissipation response to a similar accuracy, with less dependency on the soil rigidity index.

This paper has highlighted the need to assess whether the penetration response is undrained as this will affect interpretations of soil strength from the net penetration resistance. In the field tests considered here, advancing the $60 \mathrm{~mm}$

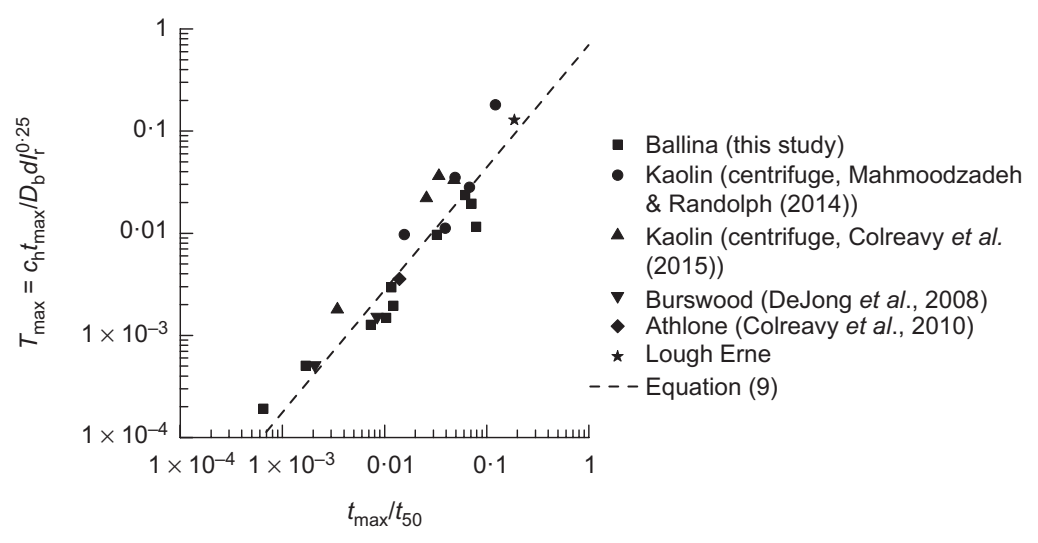

Fig. 10. Empirical method of estimating $c_{\mathrm{h}}$ from piezoball equator dissipation data 


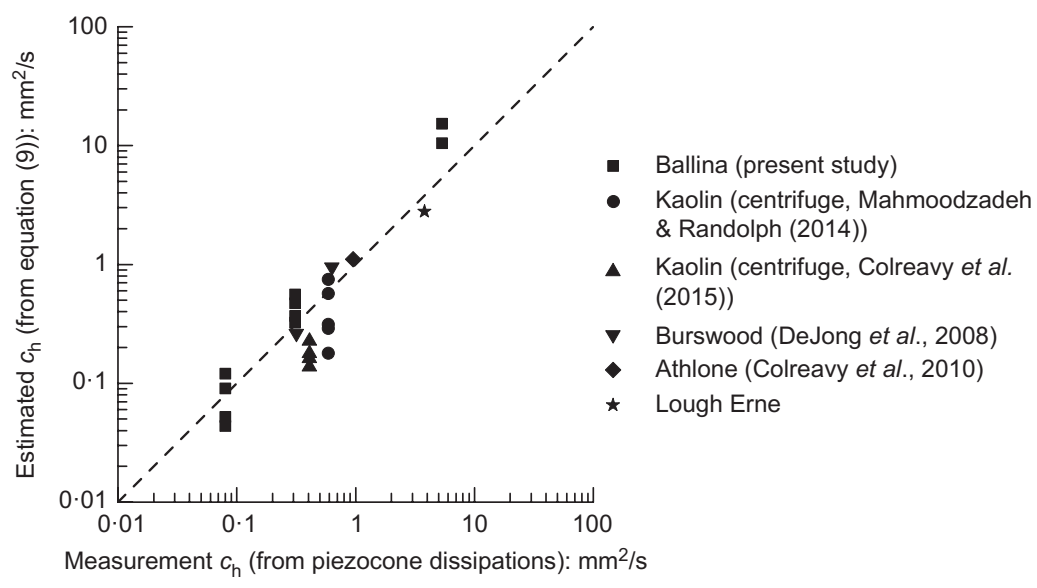

Fig. 11. Comparison of empirically derived $c_{\mathrm{h}}$ with $c_{\mathrm{h}}$ derived from piezocone dissipation tests

diameter piezoball at the standard $20 \mathrm{~mm} / \mathrm{s}$ would lead to an overestimation of the undrained shear strength by $40 \%$. Furthermore, the excess pore pressure response during dissipation is also affected by the penetration rate adopted for the preceding penetration. The most problematic condition is partially drained penetration, as $c_{\mathrm{h}}$ deduced from the subsequent dissipation may be underestimated, although generally by no more than half an order of magnitude. The pore pressure parameter for the piezoball, $B_{\text {ball }}=\Delta u_{\text {ball }} / q_{\text {bnet }}$ is shown to be a useful parameter for assessing drainage conditions during penetration. $B_{\text {ball }}$ should be monitored during penetration; available data - including the field data considered here - indicate that an undrained response is obtained at $B_{\text {ball }}=0.9$ for the piezoball mid-face location and $B_{\text {ball }}=0.5$ for the piezoball equator location, although just as for $B_{\mathrm{q}}$ these values will be affected by soil type. The horizontal coefficient of consolidation was determined from numerical solutions or from an empirical method presented in the paper. Both the empirical and numerical methods are capable of predicting $c_{\mathrm{h}}$ values derived from piezocone dissipation profiles to an accuracy that would be considered sufficient for design purposes.

\section{ACKNOWLEDGEMENTS}

This work forms part of the activities of the Centre for Offshore Foundation Systems (COFS), currently supported as a node of the Australian Research Council Centre of Excellence for Geotechnical Science and Engineering and through the Fugro Chair in Geotechnics, the Lloyd's Register Foundation Chair and Centre of Excellence in Offshore Foundations. The Lloyd's Register Foundation invests in science, engineering and technology for public benefit, worldwide.

\section{NOTATION}

$\begin{aligned} A_{\mathrm{p}} & \text { projected area of penetrometer probe } \\ A_{\mathrm{s}} & \text { projected area of penetrometer shaft } \\ B_{\mathrm{ball}} & \text { piezoball pore pressure parameter } \\ B_{\mathrm{q}} & \text { piezocone pore pressure parameter } \\ b, d, f & \text { fitting constants } \\ c_{\mathrm{h}} & \text { horizontal coefficient of consolidation } \\ c_{\mathrm{v}} & \text { vertical coefficient of consolidation } \\ D_{\mathrm{b}} & \text { piezoball diameter } \\ D_{\mathrm{c}} & \text { piezocone diameter } \\ d & \text { penetrometer shaft diameter } \\ G & \text { shear modulus of soil } \\ G_{\mathrm{s}} & \text { specific gravity } \\ I_{\mathrm{r}} & \text { rigidity index of soil }\left(G / s_{\mathrm{u}}\right) \\ N & \text { bearing capacity factor } \\ q & \text { penetration resistance }\end{aligned}$

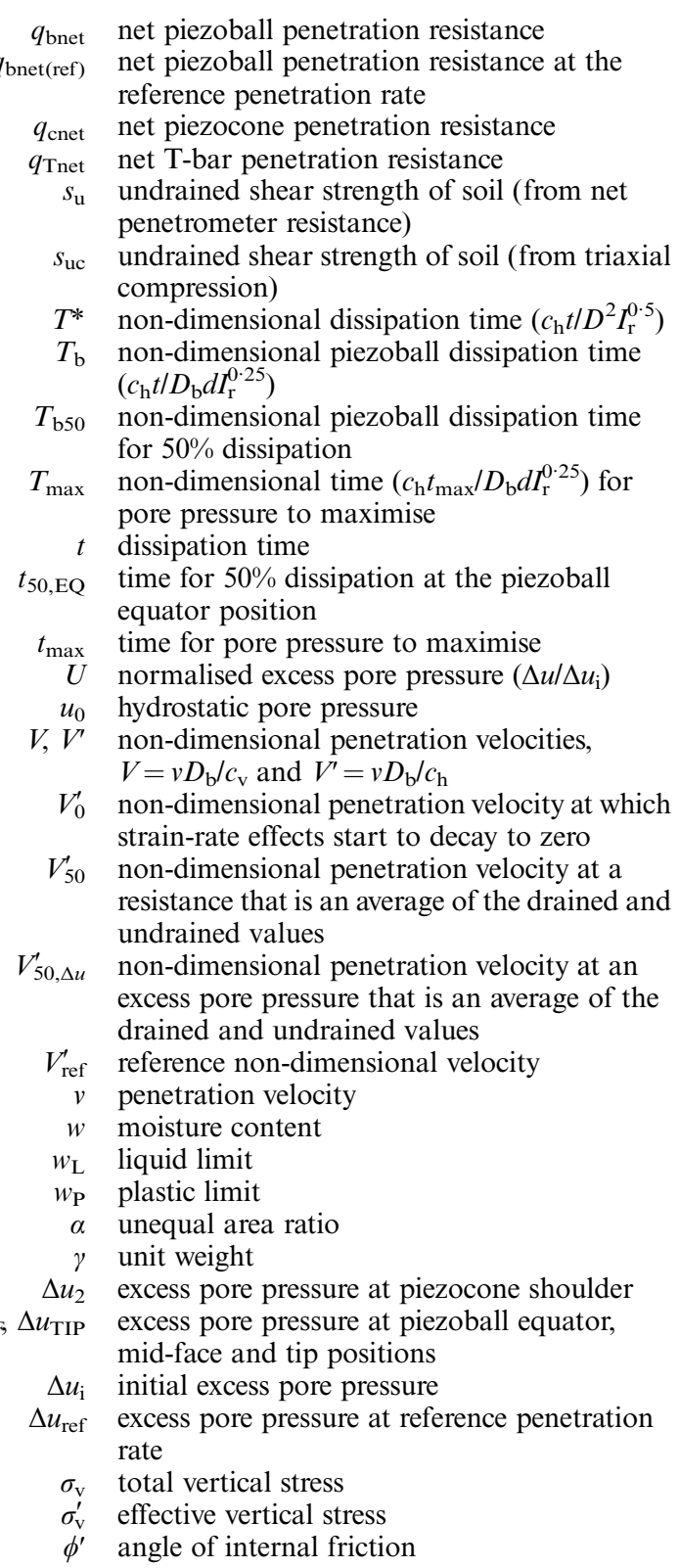

\section{REFERENCES}

Bemben, S. \& Myers, D. (1974). The influence of rate of penetration on static cone resistance values in Connecticut River valley varved clay. Proceedings of the European symposium on penetration testing - ESOPT, Stockholm, Sweden, pp. 33-37. 
Boylan, N., Long, M., Ward, D., Barwise, A. \& Georgious, B. (2007). Full-flow penetrometer testing in Bothkennar clay. In Proceedings of the 6th international offshore site investigation and geotechnics conference: confronting new challenges and sharing knowledge, pp. 177-186. London, UK: Society for Underwater Technology.

Boylan, N., Randolph, M. F. \& Low, H. E. (2010). Enhancement of the ball penetrometer test with pore pressure measurements. Proceedings of the 2nd international symposium on frontiers in offshore geotechnics - ISFOG'10, Perth, Australia, pp. 259-264.

Chai, J., Sheng, D., Carter, J. P. \& Zhu, H. (2012). Coefficient of consolidation from non-standard piezocone dissipation curves. Comput. Geotech. 41, 13-22.

Chung, S. F. \& Randolph, M. F. (2004). Penetration resistance in soft clay for different shaped penetrometers. In Proceedings of 2 nd international conference on geotechnical and geophysical site characterization - ISC 2 (eds A. V. de Fonseca and P. W. Mayne), vol. 1, pp. 671-677. Rotterdam, the Netherlands: Millpress.

Chung, S. F., Randolph, M. F. \& Schneider, J. A. (2006). Effects of penetration rate on penetrometer resistance in clay. J. Geotech. Geoenviron. Engng 132, No. 9, 1188-1196.

Colreavy, C., O'Loughlin, C. D., Long, M., Boylan, N. \& Ward, D. (2010). Field experience of the piezoball in soft clay. Proceedings of 2 nd international symposium on cone penetration testing CPT '10, Huntington Beach, USA.

Colreavy, C., O'Loughlin, C. D. \& Ward, D. (2012). Piezoball testing in soft lake sediments. In Proceedings of 4th international conference on geotechnical and geophysical site characterization - ISC 4 (eds R. Q. Countinho and P. W. Mayne), pp. 597-602. London, UK: Taylor \& Francis.

Colreavy, C., O’Loughlin, C. D. \& Randolph, M. (2015). Experience with a dual pore pressure element piezoball. Int. J. Phys. Modelling Geotech., http://dx.doi.org/10.1680/jphmg.15.00011.

DeJong, J. T., Yafrate, N. J. \& Randolph, M. F. (2008). Use of pore pressure measurements in a ball full-flow penetrometer. In Proceedings of $3 r d$ international conference on geotechnical and geophysical site characterisation - ISC 3 (eds A.-B. Huang and P. W. Mayne), pp. 1269-1276. London, UK: Taylor \& Francis.

DeJong, J. T., Yafrate, N. J. \& DeGroot, D. J. (2011). Evaluation of undrained shear strength using full-flow penetrometers. J. Geotech. Geoenviron. Engng 137, No. 1, 14-26.

Finnie, M. S. \& Randolph, M. F. (1994). Punch-through and liquefaction induced failure of shallow foundations on calcareous sediments. In Proceedings of the 7th international conference on behaviour of offshore structures, BOSS '94 (ed. C. Chryssostomidis), pp. 217-230. New York, NY, USA: Pergamon.

Gaudin, C., White, D. J., Boylan, N., Breen, J., Brown, T., De Cantania, S. \& Hortin, P. (2009). A wireless high-speed data acquisition system for geotechnical centrifuge model testing. Measmt Sci. Technol. 20, No. 9, 1-11.

House, A., Oliveiria, J. R. M. S. \& Randolph, M. F. (2001). Evaluating the coefficient of consolidation using penetration tests. Int. J. Phys. Modelling Geotech. 1, No. 3, 17-26.

Jaeger, R. A., DeJong, J. T., Boulanger, R. W., Low, H. E. \& Randolph, M. F. (2010). Variable penetration rate CPT in an intermediate soil. Proceedings of 2nd international symposium on cone penetration testing - CPT '10, Huntington Beach, USA.

Kelleher, P. J. \& Randolph, M. F. (2005). Seabed geotechnical characterisation with a ball penetrometer deployed from the portable remotely operated drill. In Frontiers in offshore geotechnics: proceedings of the international symposium on frontiers in offshore geotechnics (IS-FOG 2005) (eds S. Gourvenec and M. Cassidy), pp. 365-371. London, UK: Taylor \& Francis.

Kelly, R. B., O'Loughlin, C. D., Bates, L., Gourvenec, S. M., Colreavy, C., White, D. J., Gaone, F. M., Doherty, J. P. \& Randolph, M. F. (2014). In situ testing at the National Soft Soil Field Testing Facility, Ballina, New South Wales. Aust. Geomech. 49, No. 4, 15-28.

Lehane, B. M., O'Loughlin, C. D., Gaudin, C. \& Randolph, M. F. (2009). Rate effects on penetrometer resistance in kaolin. Géotechnique 59, No. 1, 41-52, http://dx.doi.org/10.1680/geot. 2007.00072.
Low, H. E., Randolph, M. F. \& Kelleher, P. J. (2007). Comparison of pore pressure generation and dissipation rates from cone and ball penetrometers. In Proceedings of the 6th international conference on offshore site investigation and geotechnics: confronting new challenges and sharing knowledge, pp. 547-556. London, UK: Society for Underwater Technology.

Low, H. E., Randolph, M. F., DeJong, J. T. \& Yafrate, N. J. (2008). Variable rate full-flow penetration tests in intact and remoulded soil. In Proceedings of the 3rd international conference on geotechnical and geophysical site characterisation - ISC 3 (eds A.-B. Huang and P. W. Mayne), pp. 1087-1092. London, UK: Taylor \& Francis.

Low, H. E., Lunne, T., Andersen, K. H., Sjursen, M. A., Li, X. \& Randolph, M. F. (2010). Estimation of intact and remoulded undrained shear strengths from penetration tests in soft clays. Géotechnique 60, No. 11, 843-859, http://dx.doi.org/10.1680/ geot.9.P.017.

Lu, Q., Hu, Y. \& Randolph, M. F. (2000). FE analysis for T-bar and spherical penetrometers in cohesive soil. Proceedings of the 10th international offshore and polar engineering conference, Seattle, USA, pp. 617-623.

Lu, Q., Randolph, M. F., Hu, Y. \& Bugarski, I. C. (2004). A numerical study of cone penetration in clay. Géotechnique 54, No. 4, 257-267, http://dx.doi.org/10.1680/geot.2004.54. 4.257 .

Lunne, T., Robertson, P. K. \& Powell, J. J. M. (1997). Cone penetration testing in geotechnical practice. London, UK: Blackie Academic and Professional.

Lunne, T., Andersen, K. H., Low, H. E., Randolph, M. F. \& Sjursen, M. A. (2011). Guidelines for offshore in situ testing and interpretation in deepwater soft clays. Can. Geotech. J. 48, No. 4, 543-556.

Mahmoodzadeh, H. \& Randolph, M. F. (2014). Penetrometer testing: effect of partial consolidation on subsequent dissipation response. J. Geotech. Geoenviron. Engng 140, No. 6, 1-12.

Mahmoodzadeh, H., Randolph, M. F. \& Wang, D. (2014). Numerical simulation of piezocone dissipation test in clays. Géotechnique 64, No. 8, 657-666, http://dx.doi.org/10.1680/ geot.14.P.011, also corrigendum 64, No. 10, 848-850.

Mahmoodzadeh, H., Wang, D. \& Randolph, M. F. (2015). Interpretation of piezoball dissipation testing in clay. Géotechnique 65, No. 10, 831-842, http://dx.doi.org/10.1680/ jgeot.14.P.213.

Nash, D. F. T., Powell, J. J. M. \& Lloyd, I. M. (1992). Initial investigations of the soft clay test site at Bothkennar. Géotechnique 42, No. 2, 163-181, http://dx.doi.org/10.1680/ geot.1992.42.2.163.

Pineda, J. A., Prasad Suwal, L. \& Kelly, R. B. (2014). Sampling and laboratory testing of Ballina clay. Aust. Geomech. 49, No. 4, $29-40$

Randolph, M. F. \& Hope, S. (2004). Effect of cone velocity on cone resistance and excess pore pressures. Proceedings of the international symposium on engineering practice and performance of soft deposits, Osaka, Japan, pp. 147-152.

Randolph, M. F., Cassidy, M., Gourvence, S. \& Erbrich, C. (2005). Challenges of offshore geotechnical engineering. Proceedings of the 16th international conference on soil mechanics and geotechnical engineering, Osaka, Japan, vol. 1, pp. 123-176.

Robertson, P. K. (1990). Soil classification using the cone penetration test. Can. Geotech. J. 27, No. 1, 151-158.

Roy, M., Tremblay, M., Tavenas, F. \& LaRochelle, P. (1982). Development of pore pressures in quasi-static penetration tests in sensitive clay. Can. Geotech. J. 19, No. 2, 124-138.

Sully, J. P., Robertson, P. K., Campanella, R. G. \& Woeller, D. J. (1999). An approach to evaluation of field CPTU dissipation data in overconsolidated fine-grained soils. Can. Geotech. J. 36, No. 2, 369-381.

Suzuki, Y. (2015). Investigation and interpretation of cone penetration rate effects. $\mathrm{PhD}$ thesis, University of Western Australia, Crawley, Australia.

Teh, C. I. \& Houlsby, G. T. (1991). An analytical study of the cone penetration test in clay. Géotechnique 41, No. 1, 17-34, http://dx. doi.org/10.1680/geot.1991.41.1.17.

Yafrate, N. J. \& DeJong, J. T. (2009). Evaluation of remolded shear strength and sensitivity of soft clay using full-flow penetrometers. J. Geotech. Geoenviron. Engng 135, No. 9, 1179-1189. 